\title{
BMJ Open A qualitative analysis of messages to promote smoking cessation among pregnant women
}

\author{
Janet Hoek, ${ }^{1}$ Heather Gifford, ${ }^{2}$ Ninya Maubach, ${ }^{1}$ Rhiannon Newcombe ${ }^{3}$
}

To cite: Hoek J, Gifford H, Maubach N, et al. A qualitative analysis of messages to promote smoking cessation among pregnant women. BMJ Open 2014:4:e006716

doi:10.1136/bmjopen-2014006716

- Prepublication history and additional material is available. To view please visit the journal (http://dx.doi.org/ 10.1136/bmjopen-2014006716).

Received 23 September 2014 Revised 21 October 2014 Accepted 6 November 2014

CrossMark

\begin{abstract}
${ }^{1}$ Department of Marketing, University of Otago, New Zealand

${ }^{2}$ Whakauae Research for a Māori Health and

Development, Whanganui, New Zealand

${ }^{3}$ Health Promotion Agency, Wellington, New Zealand
\end{abstract}

Correspondence to Professor Janet Hoek; Janet.hoek@otago.ac.nz

\section{ABSTRACT}

Objectives: Although aware that smoking while pregnant presents serious risks to their unborn children, some women continue to smoke and rationalise their dissonance rather than quit. We explored metaphors women used to frame smoking and quitting, then developed cessation messages that drew on these metaphors and examined the perceived effectiveness of these.

Participants: We used a two-phase qualitative study. Phase one involved 13 in-depth interviews with women who were smoking (or who had smoked) while pregnant. Phase two comprised 22 in-depth interviews with a new sample drawn from the same population.

Analyses: Data were analysed using thematic analysis, which promoted theme identification independently of the research protocol.

Results: Participants often described smoking as a choice, a frame that explicitly asserted control over their behaviour. This stance allowed them to counterargue messages to quit, and distanced them from the risks they created and faced. Messages tested in phase 2 used strong affective appeals as well as themes that stimulated cognitive reflection. Without exception, the messages depicting unwell or distressed children elicited strong emotional responses, were more powerful cessation stimuli, and elicited fewer counterarguments.

Conclusions: Cessation messages that evoke strong affective responses capitalise on the dissonance many women feel when smoking while pregnant and stimulate stronger consideration of quitting. Given the importance of promoting cessation among pregnant women, future campaigns could make greater use of emotional appeals and place less emphasis on informational approaches, which often prompt vigorous counter-arguments.

\section{BACKGROUND}

Numerous studies have documented the risks of smoking during pregnancy, including the increased risk of miscarriage, low birthweight babies, stillbirth and sudden unexpected death in infancy (SUDI). ${ }^{1}$ Children born to mothers who have smoked during pregnancy are more susceptible to respiratory infections and asthma, ${ }^{2}$ and more likely to experience

\section{Strengths and limitations of this study}

- Use of in-depth qualitative methods allowed detailed probing of a priority population group's responses to alternative smoke-free messages.

- The findings illustrate the importance of high affect-arousing messages and reveal informational strategies that are less impactful and less likely to motivate behaviour change.

- The stigma associated with smoking while pregnant complicated participant recruitment and resulted in a more attenuated data collection period. Nevertheless, interviewing continued until data saturation was achieved.

- The study did not involve a direct intervention; thus, the behavioural effects of the messages tested cannot be estimated.

learning and cognitive development disorders. ${ }^{3}$ These and the increased risks of other chronic diseases throughout childhood ${ }^{4}$ mean that women who are pregnant and smoking are strongly advised to quit. However, many continue to smoke during and beyond pregnancy, putting themselves and their children at risk. ${ }^{56}$

Women who smoke while pregnant often have fewer qualifications, come from poorer communities where smoking is more prevalent, ${ }^{7-9}$ and experience a reduced urgency to quit. ${ }^{4} 1011$ Because smoking is entrenched in some communities, women often see other women smoking while pregnant, and may themselves have been born to smokers. ${ }^{12}$ The reported harms of smoking during pregnancy may diverge from their own experiences and the absence of overt or perceived harm may imply that continued smoking does not inevitably harm unborn children. ${ }^{12-14}$ Women who smoke while pregnant (or who smoke following the birth of their child) may also see quitting as segregating them from social networks at the very time they would like greater support, ${ }^{6}{ }^{15}$ and report that smoking fosters social interactions, provides respite from monotonous jobs and represents opportunities to relax. ${ }^{5} 11$ 16-20 
Promoting the health risks of smoking during pregnancy may thus fail to trigger quit attempts because the distal risks smokers perceive as uncertain fail to outweigh the proximal benefits they receive. ${ }^{8}{ }^{21}$ Cessation messages must decrease the value placed on smoking as a reward, offer alternatives, challenge the myths and self-exempting beliefs pregnant smokers construct, and provide stimuli that prompt and support quit attempts. ${ }^{9} 22$ They must balance the risk that dissonance inducing messages promote reactance and counterargument rather than action, and leave behaviour more ingrained. ${ }^{23}$

\section{Dissonance and reactance}

Conflicting beliefs and behaviours create tension that may promote behaviour change as individuals try to align their thoughts, feelings and actions to reduce discord. ${ }^{24}$ Smokers may experience dissonance in social settings, where smoking has become increasingly unacceptable, and when reflecting on the harm smoking causes to themselves or others. ${ }^{25}$ The resulting unease may provide a powerful stimulus that potential cessation messages could utilise.

However, while cognitive dissonance should logically foster quit attempts, behaviour change is not always straightforward, even when dissonance is high and uncomfortable. For example, addicted smokers may struggle to quit, despite wishing to become smokefree. ${ }^{13} 26$ Tensions caused by discrepancies between smokers' beliefs, a desire to quit and continued smoking may become acute among women who are pregnant and smoking. Advice to quit from healthcare providers may exacerbate these tensions, as may the strong social disapproval these women risk attracting from individuals outside their immediate family or peer networks. ${ }^{7} 121920$ Overt censure from strangers who do not condone smoking during pregnancy may also trigger strong guilt that stimulates either quit attempts or reactance, or both. ${ }^{1720}$

Women unable or unwilling to quit may rationalise their continued smoking by discounting the risks they face or asserting their invulnerability to these. ${ }^{25} 2728$ For example, they may interpret their own perceived wellbeing as a sign they do not face the risks others face, while the apparent health of other smokers' babies may reinforce beliefs that smoking is not inevitably harmful. ${ }^{22} 27$

However, while these approaches might counter cognitive dissonance, affective dissonance may be less easily resolved. Arousal of negative emotions such as shock, horror and fear could increase the affective element of risk perception, reduce feelings of immunity, and heighten the urgency of behaviour change. ${ }^{29}$ Research to date suggests cessation messages that elicit strong emotional reactions provoke fewer counter-arguments than more informational approaches ${ }^{30}$ and have stronger effects on lower socioeconomic smokers, where smoking prevalence is higher. ${ }^{29} 31$
We used this emotion-dissonance framework to explore how women who are pregnant and smoking (or who gave birth within the past year and smoked while pregnant) resolve the tensions they face. Specifically, we sought to identify messages that would promote smoke-free behaviour during and following pregnancy. We began by exploring the metaphors participants used to interpret smoking and quitting. Next, we translated these metaphors into cessation messages that included strong negative affect-arousing themes as well as more informational approaches, and explored responses to these. Specifically, we addressed the following research questions:

RQ1: What metaphors do pregnant smokers use to interpret smoking and quitting?

RQ2: How do women who are pregnant and smoking interpret and respond to cessation messages that challenge these metaphors and the rationalizations they support?

\section{METHODS}

Phase 1 involved in-depth interviews with 13 pregnant women and/or women who had given birth within the past year. In-depth interviews recognised the stigma associated with smoking during pregnancy and so provided participants with privacy. In addition, this approach allows detailed probing of responses, which was important to test interpretations of the alternative messages tested.

The second phase comprised in-depth interviews with a new sample of 22 women. For both phases, we recruited a convenience volunteer sample using community advertising, via affinity groups, and through advertising at an antenatal clinic. Although this approach recognised the difficulty of recruiting study participants, we nevertheless achieved demographic diversity among participants, as table 1 illustrates.

Each participant received an information sheet explaining the study and their rights as participants, and gave written consent prior to the interview. Participants were assured of confidentiality and all identifying information was destroyed once the recordings had been transcribed and checked. Table 1 summarises participants' characteristics.

\section{Procedure}

Phase 1 involved a team of six interviewers (who corresponded to the participants' ethnicity); the relatively large and diverse team enabled multiple perspectives to inform the study design and data interpretation, and provided many opportunities for each researcher to reflect on her perspective. Interviewers used 32 images in a photo sort task to explore how participants perceived smoking, being smoke free and quitting. We sourced images from other campaigns and also used suggestions from our wider research team to identify and select images that could correspond to perceived rewards of smoking. Participants classified the images according to whether these connoted positive or 
Table 1 Demographic characteristics of participants

\begin{tabular}{|c|c|c|}
\hline Participants' characteristics & Phase 1 & Phase 2 \\
\hline \multicolumn{3}{|l|}{ Education } \\
\hline No formal qualifications & 3 & 4 \\
\hline School level qualifications & 6 & 12 \\
\hline Certificate (trade qualification) & 1 & 4 \\
\hline Bachelor's degree & 2 & 1 \\
\hline Postgraduate & 1 & 1 \\
\hline \multicolumn{3}{|l|}{ Age } \\
\hline Mean & 29 & $24^{*}$ \\
\hline Range & $17-43$ & 17-39 \\
\hline \multicolumn{3}{|l|}{ Smoking status } \\
\hline Daily & 10 & 17 \\
\hline Intermittent & 1 & 1 \\
\hline Quit attempt underway & 2 & 4 \\
\hline \multicolumn{3}{|l|}{ Ethnicity ${ }^{\star}$} \\
\hline NZ European/other† & 2 & 9 \\
\hline Māorił & 6 & 6 \\
\hline Pacific§ & 5 & 7 \\
\hline \multicolumn{3}{|c|}{$\begin{array}{l}\text { *Data missing from two respondents. } \\
\text { †NZ European respondents are descended from European } \\
\text { settlers who colonised New Zealand during the nineteenth } \\
\text { century. } \\
\text { †Māori are the indigenous people of New Zealand. } \\
\text { §Pacific women identify with one (or more) of the island nations in } \\
\text { the South Pacific region. }\end{array}$} \\
\hline
\end{tabular}

negative attributes about smoking; they then discussed the three images they thought best illustrated each dimension. Table 2 contains details of these images, which may not be printed for copyright reasons.

The 22 phase 2 participants reviewed 9 test print advertisements that were informed by the phase 1 findings and designed specifically for this study. The messages used affective and cognitive approaches in three ways. The first set featured seriously unwell babies and stressed the risk vulnerable children faced from those who exposed them to smoke. The second theme focused on parents' desire to see their children grow up safely and the difficulties children could face if their parents died prematurely. The final theme promoted cessation as a rational response to smokers' latent desire to quit and offer their children a smoke-free environment. Owing to copyright restrictions, the images cannot be shown but Table 3 summarises their content and copies may be obtained from the lead author for private use only. Details of both interview protocols are available as additional files.

Interviews for both phases typically lasted between 40 and $60 \mathrm{~min}$, including completion of a brief questionnaire collecting demographic and reported smoking behaviour. Copies of the interview protocols used in each phase are provided as online supplementary files. Interviews were typically conducted in participants' homes, but some took place in work and study settings. Participants in each phase received a $\$ 40$ gift voucher in recognition of any costs they may have incurred to participate in the study. Recordings were reviewed following each interview to assess whether new idea elements continued to emerge; where two consecutive recordings revealed no new themes, we determined that data saturation had occurred.

\section{Data analysis}

Each interviewer interpreted her transcripts independently, using an iterative process to identify idea elements and recurring metaphors. Draft interpretations were then discussed within the research team, retested against the transcripts, and used to identify the overarching imagery and themes. The lead author reviewed all transcripts and regular team discussions ensured the themes identified were tested for coherence and validity.

We analysed the interview transcripts using discourse analysis, which views language as a social function that participants use to construct a reality. ${ }^{32}{ }^{33}$ Discourses reflect common assumptions, reveal how these structure participants' thoughts and actions, and uncover how participants privilege some positions while minimising those that challenge their 'reality'. ${ }^{34}$ This approach enabled us to explore what emotions the messages elicited, which metaphors they employed, and how this imagery functioned. ${ }^{34}$ We use quotations to illustrate the metaphor patterns and the interpretations at which we arrived.

\section{RESULTS}

\section{Phase 1: The illusion of choice and control}

Responses to the photo sort task revealed two dominant metaphors: choice and control. Participants resisted acknowledging they were addicted by asserting smoking as a choice over which they maintained control. Yet despite constructing this position, none described smoking as a conscious choice and nearly all began smoking to avoid deviating from the peer group and family social norms: "We were raised in a smoking house...there was just smoke... It wasn't really peer pressure or 'cause it was just to be cool, 'cause everybody else was doing it at the time." These comments highlight the pervasiveness and normality of smoking, where 'everybody else' and 'everyone' smoked: "When I was going out [to pubs] all the time and everyone was just smoking outside, so that's mainly why I started." Smoking defined group membership; rather than reflecting deeply on their actions, participants adopted behaviours others modelled: "Yeah. It means a lot. It means like- ah, um, I can actually smoke. I can actually afford a smoke, and I can, um, actually, um, be my boss." Despite the apparent passivity of their smoking initiation, smoking provided participants with a tool they used to assert their social identity.

While they had not made active choices to smoke, participants nevertheless regarded smoking and quitting as a choice that only they (or other smokers) could make. They saw choice as a personal entitlement: “...it's my choice. Freedom of choice”; a general right: “... these guys [smokers] have made the choice ...", and a national freedom: "It's New Zealanders' choice... if they wanna quit they'll quit." By framing smoking and 
Table 2 Initial phase stimuli

\begin{tabular}{|c|c|}
\hline Number & Description \\
\hline 1 & $\begin{array}{l}\text { Community cessation booth in local shopping centre } \\
\text { showing smoker receiving quit advice from a quit-card } \\
\text { provider }\end{array}$ \\
\hline 2 & $\begin{array}{l}\text { Young girl using an asthma inhaler in a playground } \\
\text { area. }\end{array}$ \\
\hline 3 & $\begin{array}{l}\text { Young Pacific girl wearing a tobacco-free Pasifika } \\
\text { T-shirt }\end{array}$ \\
\hline 4 & $\begin{array}{l}\text { Group of four Maori women outside smoking during } \\
\text { a work break }\end{array}$ \\
\hline 5 & $\begin{array}{l}\text { In-store display of tobacco products, framed by } \\
\text { confectionery }\end{array}$ \\
\hline 6 & Smoker rolling a "roll-your-own" cigarette \\
\hline 7 & Women smoking outside workplace \\
\hline 8 & Female celebrity smoking during a performance \\
\hline
\end{tabular}

Theme

Empowering smokers to quit when they are ready

Negative effects of second-hand smoke on those who cannot avoid exposure

Creating a tobacco-free world for children

Shows negative effects of addiction; unglamorous image, but also camaraderie of smoking

Illustrates how tobacco is positioned as a normal product and presents a "child's-eye" view

Positive connotations of anticipation and the "art of rolling", negative connotations of addiction Positive connotations of smoking in a social setting, negative connotations of addiction

Positive connotations of glamour and celebrity endorsement; negative connotations of poor role-modelling

Positive connotations of smoking and relaxation a public space

10 Pacific woman smoking alone outside

11 Cigarette butts in ashtray; one stick has 'cancer' written on it

12 Woman's hand holding lit cigarettes with a small child in the background

13 Woman smoking inside car (window slightly open); school age girl looking uncomfortable in back Woman lighting cigarette at isolated beach

Large pile of cigarette butts dumped at side of country road

Stressed-looking woman smoking

Woman smoking with back to partner, taking time out during an argument

Group smoking on street during winter

Young woman smoking and eating an ice cream

One woman in a group smoking outside café in winter

Two men, one blue-collar and one white-collar, taking a 'smoko' break on the street outside a building Image of dollar note being lit like a cigarette

Two men sitting on a bench at a "smoko" break; one is smoking

25 Māori warrior

$26 \quad$ Elderly woman lighting a cigarette from the candle on a 100 th birthday cake

Positive connotations of a break; negative connotations of ostracism

Negative connotations of health consequences of smoking

Negative connotations of second-hand smoke and poor role modelling

Negative consequences of exposing others to second-hand smoke

Positive connotations of having time out relaxing; negative connotations of smoking and litter in a natural area Negative connotations of litter and lack of thoughtfulness

Positive connotations of smoking as a means of relieving stress

Positive connotations of smoking as a means of relieving stress

Positive connotation of group activity; negative connotation of smoking outside in cold weather and ostracism

Positive association of smoking and fun

Positive connotations of smoking as a social and accepted group activity

Positive connotations of social group; negative connotations of being outside and the only one to smoke

Positive connotation of shared behaviour; negative connotation of footpath smoking near a no smoking sign Negative connotation of the cost of smoking Negative connotation of distance between then and smoking under a no smoking sign

Negative connotation of smoking as Māori had a tupeka kore (tobacco free) society prior to European colonisation Positive connotation to suggest smokers can live longer lives; negative connotations as smoking is not depicted as glamorous

Positive connotations of quitting; negative connotations of NRT side effects Negative connotations of harm to unborn child 
Table 2 Continued

\begin{tabular}{lll}
\hline Number & Description & Theme \\
\hline 29 & Sonny Bill Williams, a rugby and rugby league hero & $\begin{array}{l}\text { Negative connotations as it suggests the importance of } \\
\text { health to a high-level sporting personality } \\
\text { Positive connotations regarding smoke-free areas for } \\
\text { children; negative reflections on children's exposure to } \\
\text { second-hand smoke and smoking role models }\end{array}$ \\
& Smoke-free sign in playground & $\begin{array}{l}\text { Negative connotations of addiction. } \\
\text { Positive connotations of asserting control over smoking }\end{array}$ \\
31 & Cigarettes displayed as a spider's web. &
\end{tabular}

NRT, nicotine replacement therapy.

quitting as "choices", participants maintained control and distanced themselves from stereotypes of addicted smokers who had lost control. This metaphor maintained the belief their situation could change and created a protective barrier they used to deflect health advice that impinged on their perceived autonomy: "I pretty much just tell them [health professionals] what I tell everybody else. I'm gonna do what I wanna do when I wanna do it and no one can tell me otherwise."

Despite asserting their 'choice', many participants struggled to maintain this privileged position of control because nearly all had tried but failed to quit while pregnant. While some women had made a quit attempt because they were advised to do so by their midwife, others had tried to stop smoking because they recognised the harms continued smoking presented to their unborn child. Women in this latter group had to contend with ongoing complications and the guilt these caused: "I always blame myself because I know it was my smoking... I don't want to have another sick baby" and all felt the stigma of smoking while pregnant: "you know ...it just looks wrong. You know, you feel bad. You feel really bad and you feel guilty." The resulting dissonance weighed heavily as women wanted the best outcomes for their children, even though their continued smoking conflicted with this goal.

While a minority acknowledged their smoking was controlled by an addiction, the general dominance of control and choice metaphors in participants' discourse suggested three potential cessation message themes that we developed and tested in phase 2. The first two used affect-laden approaches to challenge the reasoned positions smokers had constructed. Specific messages illustrated the effects of smoking on babies who had no choice in being exposed to toxins, and the consequences children face when their parents are harmed by smoking. The final theme used a rational approach to support smoke-free behaviours; messages recognised smokers' autonomy and promoted children's right to a smoke-free life.

Table 3 Message stimuli tested

\begin{tabular}{|c|c|}
\hline Number & Description \\
\hline 1 & $\begin{array}{l}\text { Young boy crying. Headline reads: "If this is how your } \\
\text { child feels after losing you for a minute, just imagine if } \\
\text { they lost you for life" }\end{array}$ \\
\hline 2 & $\begin{array}{l}\text { Young Pacific girls with a toy. Headline reads: "What's } \\
\text { worse than hearing your doctor say: 'You've got } \\
\text { cancer?': Telling your family" }\end{array}$ \\
\hline 3 & $\begin{array}{l}\text { Young girl shaping fingers into a heart. Headline reads: } \\
\text { "Quit for those who love you" }\end{array}$ \\
\hline 4 & $\begin{array}{l}\text { Community cessation booth. Headline reads: "When } \\
\text { you decide to be smokefree, we'll be here to help you." }\end{array}$ \\
\hline 5 & $\begin{array}{l}\text { Children in playground. Headline reads: "All children } \\
\text { have the right to a smoke-free childhood" }\end{array}$ \\
\hline 6 & $\begin{array}{l}\text { Image of unborn child. Headline reads: "There is no } \\
\text { such thing as a safe cigarette" }\end{array}$ \\
\hline 7 & $\begin{array}{l}\text { Pregnant woman with one hand on stomach, other } \\
\text { hand holding a cigarette. Headline reads: "You can't } \\
\text { hide it from your baby" }\end{array}$ \\
\hline 8 & $\begin{array}{l}\text { Baby girl on oxygen machine; has a bow in her hair. } \\
\text { Headline reads: "Smoking cuts off your baby's oxygen } \\
\text { supply" }\end{array}$ \\
\hline 9 & $\begin{array}{l}\text { Premature baby on respirator. Headline reads: "If you } \\
\text { plan to get pregnant, then plan to quit first" }\end{array}$ \\
\hline
\end{tabular}

Theme

Evokes concern for children whose parents die from tobacco-related diseases

Evokes concern for children whose parents die from tobacco-related diseases

\section{Evokes concern for children exposed to second-hand smoke}

Uses a rational appeal that focuses on choice and offers support to those who have chosen to quit

Uses a rational appeal that focuses on choice and urges adults to provide smoke-free environments for children Evokes concern for vulnerable unborn child

Evokes concern for vulnerable unborn child

Evokes concern for newborn children whose mothers smoked while pregnant

Evokes concern for newborn children whose mothers smoked while pregnant 
Phase 2: Affect, responsibility and reason

The first two themes depicted unwell babies and showed the distress of children who could become tobacco orphans; these messages elicited strong emotional reactions from participants. Comments focused on how smoking would harm unborn children, and participants often used words such as 'suffer', 'affect' and 'feel': "no matter who you hide it from, the child will still suffer for it", and "your baby's always going to feel it so he'll know you're smoking." These emotionally-laden responses recognised that children lacked choice and would bear the consequences of their mothers' actions: "for something so little and small that hasn't even entered this world yet, already they have chances taken from them." The strong emotional engagement with the messages meant very few advanced counter-arguments.

Feelings of fear and shame elicited directly challenged participants' behaviour: "I think that's so sad....It's like you're responsible... like they can't make choices for themselves... Like you've gotta make the right ones for them." Confronting the effects their actions could have on their unborn child evoked high levels of dissonance: "I did feel so guilty and you did try and hide it.... Either try and hide the smoke or baby bump-especially when you were out in public." Participants empathised strongly with the images of overt harm and distress shown and could not avoid the conclusion they might be causing their own child to suffer: "pictures of children and young babies and stuff make you think a lot more about it, not doing it."

The affect-arousing images contrasted strongly with the existing health warnings they saw featured on tobacco packages, and that they found easy to counterargue: "Oh, just the ones with like the foot with the tag on it...and the picture of any eye and, y-you look at those ones and you're like "ohh.....mine's never gonna look like that." Whereas having pictures of young children and you think of your own child and you think, yes, my own child would look like that if I was gone or ... that could be my own baby being like that due to my smoking, so it really-they just make you think a lot more about not doing it." While lifeless diseased organs were easily dismissed as irrelevant, participants found the poignant images of unwell children difficult to rationalise or ignore.

Participants again used metaphors such as 'choice', 'chance', 'fairness' and 'rights', and supported messages that questioned whether children exposed to smoke enjoyed these rights: "they—children and babies-have the right to a smoke free world and yet they don't have that choice at all." Having argued in favour of their own rights, many saw how their behaviour affected their children: "You know-why make them suffer for a decision when it's just something that we want to do? It's not fair." This reflection promoted empathy and pathos: "I think it's sad... that the kid don't get the choice to-you know-make that choice, ...that the Mum's just taken it away."
Despite asserting their own right to choose whether they smoked or tried to quit, participants found confronting the consequences of their choices disturbing. They responded instinctively to images showing the harms babies of smokers could suffer: "It would make me wanna quit... That's a-a jolt... You can't ignore that. You can't walk away from that." The rationalisations they had previously constructed crumbled as they saw the reality their children could face: "it's like well you can't argue when you've got the picture there. My brain can't justify anything on that. It's just that simple."

However, messages that asserted children's rights without showing direct harm did not evoke high levels of emotion and had correspondingly weaker effects: "it's kind of funny when you think about when they're inside your womb...because ... you can't actually see them you think that you're doing something that it's not really... affecting them, yet it really is." The limits of rational evidence are clear; the participant knows smoking harms her unborn child and agrees that smoking while pregnant is not 'right'; however, without clear visual evidence, she finds it hard to appreciate the risk she is creating.

Although messages arousing strong negative affect were consistently seen as more effective across all ethnicities, participants preferred less didactic messages: "like it doesn't say that you should quit- like it's not so-'oh you're a bad mum-you're smoking-you know you should stop smoking'-it's kind of saying that you do have a choice." These messages offered nonjudgemental support, stressed quitting was a positive personal choice, and maintained participants' autonomy: "It's-it's saying like 'when you're ready' not like somebody trying to push you to it-to quit....Just with the fact that there's um-freedom of choice.... You know. It's your choice. It's not like somebody nagging at-on you."

However, while participants often resented being advised to quit, they saw messages that appealed to their autonomy as less effective and were more likely to counter-argue these. For example, one message suggested children's spaces, such as playgrounds, should be smoke-free: "if I was there [in a smokefree playground] I'd be way over there away from them smoking so it wouldn't really affect them. Like that's my mind working it out. There's nothing too bad about it." These rationalisations typically privileged participants' rights: "In a way I agree but in a way I don't because basically that's taking away your right to like, example, smoke in your own home..., it's taking away your rights." Cognitive appeals almost invariably led participants to assert their rights over those children might enjoy, and some reacted strongly against initiatives that they thought would curtail these perceived rights.

Although participants were much more likely to counter-argue rational messages than negative-affect messages, even the latter still provoked some psychological reactance. Women who had not made a quit attempt since becoming pregnant were more likely to 
offer rationalisations that enabled them to minimise the risk of smoking and the harm that could result: "With my first two I gave up smoking, and then my sister was smoking when she had her baby and her baby came out perfect, so when I had my third one I was smoking.... and she's all right." Some also queried the inevitability of harm or attributed harm to other causes: "Some mothers-no matter not smoking-they still have prem [premature] babies, you know.. like I said, smoking isn't the only cause to-for this particular thing." Nevertheless, even the minority advancing these rationalisations felt unsettled by the images shown, which they conceded were disturbing.

\section{DISCUSSION}

Participants recognised smoking was harmful and, despite strenuous efforts to assert they chose to smoke, most regretted smoking while pregnant and nearly all had attempted to quit. Their comments revealed tensions between the belief they chose to smoke, the addiction that undermined this belief, and the potential consequences they tried to rationalise. ${ }^{1423}$ Choosing to smoke implied control and power; participants sought this status as it maintained their belief they could also choose to quit. ${ }^{413}$ However, the dissonance between this desire, the constraint addiction placed on their choice, and the negative outcomes of smoking on their children troubled them.

Messages that applied the metaphor of choice and control to quitting and protecting babies' and young children's health provided participants with new motivation to quit and avoided the reactance more didactic messages evoked. ${ }^{26}$ Women's instinctive desire to protect their children meant images of ill and vulnerable babies and children, or showing children bereft of care, cut through rationalised defences and elicited strong selfreferent emotions. ${ }^{29} 31$ The unambiguous messages reached participants in a way rational arguments had not, leaving most unable to counter-argue or rationalise their behaviour. ${ }^{13} 2526$ However, a minority rejected messages promoting cessation as a positive choice and drew on their own experiences to question the argument's credibility. ${ }^{14} 30$ While reframing choice from a child's perspective creates a strong cessation impetus and could stimulate participants to assert and act on their desire to protect their children, it is unlikely to be the panacea that eliminates smoking during pregnancy and should not pre-empt action in other domains. ${ }^{7}$ Women's social environment remains a crucial determinant of their smoking behaviour; more effective social marketing messages may stimulate quit attempts, but the success and duration of these will also depend on the support they receive. ${ }^{5} 161922$

Although interviewing in each phase continued until saturation, study limitations include the comparatively small samples and the difficulty of recruiting participants in this highly stigmatised population. While a small number of participants had successfully quit smoking during their pregnancy, most had continued, despite having tried to quit. Nearly all participants acknowledged smoking during pregnancy put their unborn child at risk of serious illnesses. These responses may reflect social desirability error; however, marked variations in how participants rationalised their behaviour suggests sample members held diverse views, even if they shared a common behaviour. In addition, while we explored participants' interpretations of messages and their responses to these, we did not test their actual behaviour.

Our findings support greater use of high affect-arousing messages as these achieved a cut-through not observed in informational approaches; metaphors deemed didactic fared poorly and future strategies should avoid using this approach. Mass media social marketing campaigns are expensive to reach a very specific population group and networking with antenatal care providers, who are required to identify whether their clients smoke, could promote greater message uptake and responsiveness.

Future work could focus on women holding hardened attitudes as their stronger counter-arguments suggest they require different messages, or different interventions, before feeling prompted to make a quit attempt. Such work may be challenging in countries where policies have strongly denormalised smoking and arguably created disincentives for smokers to self-identify. ${ }^{12}{ }^{17}$ Translating the messages we found effective into interventions would enable the examination of cessationlinked responses among women and those in their immediate social network. ${ }^{16}{ }^{20}$ A quantitative study estimating how women of childbearing age who smoke respond to the messages our participants regarded as most effective could examine how our findings predict population-level responses. Such a study could estimate how likely respondents are to quit before becoming pregnant, or on learning they are pregnant, and would provide direct guidance to policymakers. While these studies could not determine causality, they would nevertheless enable comparison of the messages' relative effects. Future work could also explore how effectively the messages tested maintain smoke-free behaviour, particularly postpartum, when relapse is common. ${ }^{6} 2035$

\section{CONCLUSIONS}

Knowledge of the metaphors on which smokers rely and the rationalisations these support informed new message strategies, the most effective of which focused on affect rather than cognitions. Specifically, framing smoking not as an assertion of women's choices, but as a behaviour that deprives children of the freedom to make choices, offers a new approach to promoting cessation to pregnant women.

In line with conceptual and empirical studies foregrounding the primacy of affective responses, messages that aroused strong self-referent emotions created dissonance less amenable to counter-argument. Generating 
affective, rather than cognitive, dissonance appears to have a stronger cut-through than informational or didactic messages. Our findings have two key implications. First, they suggest policymakers could diversify their current approaches to behaviour change, which assume a rational decision-making process in which few consumers engage. Second, our results offer social marketers a potentially more effective new approach to designing interventions for this high priority population group. Specifically, we suggest there is potential value in testing the most effective messages in targeted communications that reach women when they are in healthcare settings where cessation support is available.

Acknowledgements The authors wish to acknowledge Stephanie Erick, who reviewed the protocol for the phases and collected data from Pacific participants, and Richard Edwards, who acted as scientific advisor and provided feedback on both protocols. We also acknowledge Julie Jeon, the graphic artist who created the test advertisements used in phase 2.

Contributors $\mathrm{JH}$ was the project leader; she obtained funding for the project, led the research design, collected data and prepared the manuscript. HG provided a Māori perspective on the protocol and manuscript, and collected and interpreted data from Māori participants. NM was the project manager; she collected and interpreted the data, and reviewed the manuscript. RN provided detailed feedback on the research design, data interpretation and manuscript. All authors have approved the submitted manuscript and agree to be responsible for the data reported.

Funding Funding for the project was provided by the New Zealand Ministry of Health. We had full responsibility for the study design, data collection and analysis, report writing and the preparation of this manuscript. We had full access to all of the data in this study and take complete responsibility for the integrity of the data and the accuracy of the data analysis.

Competing interests None.

Ethics approval Ethics approval was granted by a delegated authority from the University of Otago Human Ethics Committee; additional approval was granted by the New Zealand Ministry of Health Multi-region ethics committee prior to recruitment via antenatal clinics (MEC/12/EXP/020).

Provenance and peer review Not commissioned; externally peer reviewed.

Data sharing statement No additional data are available.

Open Access This is an Open Access article distributed in accordance with the Creative Commons Attribution Non Commercial (CC BY-NC 4.0) license, which permits others to distribute, remix, adapt, build upon this work noncommercially, and license their derivative works on different terms, provided the original work is properly cited and the use is non-commercial. See: http:// creativecommons.org/licenses/by-nc/4.0/

\section{REFERENCES}

1. Herrmann M, King K, Weitzman M. Prenatal tobacco smoke and postnatal secondhand smoke exposure and child neurodevelopment. Curr Opin Pediatr 2008;20:184-90.

2. McLeod D, Pullon S, Cookson T. Factors that influence changes in smoking behaviour during pregnancy. N Z Med J 2003;116:U418.

3. Piper BJ, Gray HM, Birkett MA. Maternal smoking cessation and reduced academic and behavioral problems in offspring. Drug Alcohol Depend 2012;121:62-7.

4. Lu Y, Tong S, Oldenburg B. Determinants of smoking and cessation during and after pregnancy. Health Promot Int 2001;16:355-65.

5. Bullock LFC, Mears JLC, Woodcock C, et al. Retrospective study of the association of stress and smoking during pregnancy in rural women. Addict Behav 2001;26:405-13.
6. Simonelli MC, Velicer WF. Cluster subtypes appropriate for preventing postpartum smoking relapse. Addict Behav 2012;37:280-6.

7. Ebert LM, Fahy K. Why do women continue to smoke in pregnancy? Women Birth 2007;20:161-8

8. Kahn RS, Certain L, Whitaker RC. A reexamination of smoking before, during, and after pregnancy. Am J Public Health 2002;92:1801-8.

9. Maxson PJ, Edwards SE, Ingram A, et al. Psychosocial differences between smokers and non-smokers during pregnancy. Addict Behav 2012;37:153-9.

10. DiClemente CC, Dolan-Mullen $\mathrm{P}$, Windsor RA. The process of pregnancy smoking cessation: implications for interventions. Tob Control 2000;9(suppl 3):iii16-21.

11. Wakefield M, Gillies $P$, Graham $H$, et al. Characteristics associated with smoking cessation during pregnancy among working class women. Addiction 1993;88:1423-30.

12. Ingall G, Cropley M. Exploring the barriers of quitting smoking during pregnancy: a systematic review of qualitative studies. Women Birth 2010;23:45-52.

13. Wakefield MA, Jones WR. Cognitive and social influences on smoking behaviour during pregnancy. Aust N Z J Obstet Gynaecol 1991;31:235-9.

14. Tombor I, Urbán R, Berkes $\mathrm{T}$, et al. Denial of smoking related risk among pregnant smokers. Acta Obstet Gynecol Scand 2010;89:524-30.

15. Tod AM. Barriers to smoking cessation in pregnancy: a qualitative study. Br J Community Nurs 2003;8:56-64.

16. Nguyen S, Von Kohorn I, Schulman-Green D, et al. The importance of social networks on smoking: perspectives of women who quit smoking during pregnancy. Matern Child Health J 2012;16:1312-18.

17. Hotham ED, Atkinson ER, Gilbert AL. Focus groups with pregnant smokers: barriers to cessation, attitudes to nicotine patch use and perceptions of cessation counselling by care providers. Drug Alcohol Rev 2002;21:163-8.

18. Loukopoulou A, Vasiliou M, Behrakis P. Interventions for smoking cessation during pregnancy. Pneumon 2011;24:66-76.

19. Edwards N, Sims-Jones N. Smoking and smoking relapse during pregnancy and postpartum: results of a qualitative study. Birth 1998;25:94-100.

20. Flemming $\mathrm{K}$, Graham $\mathrm{H}$, Heirs $\mathrm{M}$, et al. Smoking in pregnancy: a systematic review of qualitative research of women who commence pregnancy as smokers. J Adv Nurs 2013;69:1023-36.

21. Ripley-Moffitt CE, Goldstein AO, Fang WL, et al. Safe babies: a qualitative analysis of the determinants of postpartum smoke-free and relapse states. Nicotine Tob Res 2008;10:1355-64.

22. Bull L, Burke R, Walsh S, et al. Social attitudes towards smoking in pregnancy in East Surrey: a qualitative study of smokers, former smokers and non-smokers. J Neonatal Nurs 2007;13:100-6.

23. Burgess DJ, Fu SS, van Ryn M. Potential unintended consequences of tobacco-control policies on mothers who smoke: a review of the literature. Am J Prev Med 2009;37(2, Suppl 1):S151-S58.

24. Festinger L. A theory of cognitive dissonance. California: Stanford University Press, 1975.

25. McMaster C, Lee C. Cognitive dissonance in tobacco smokers Addict Behav 1991;16:349-53.

26. Haslam C, Draper E, Goyder E. The pregnant smoker: a preliminary investigation of the social and psychological influences. $J$ Public Health Med 1997;19:187-92.

27. Chapman S, Wong WL, Smith W. Self-exempting beliefs about smoking and health: differences between smokers and ex-smokers. Am J Public Health 1993;83:215-19.

28. Hoek J, Maubach N, Stevenson R, et al. Social smokers' management of conflicted identities. Tob Control 2013;22:261-5.

29. Dunlop S, Wakefield M, Kashima Y. Can you feel it? Negative emotion, risk, and narrative in health communication. Media Psychology 2008;11:52-75.

30. Hoek J, Hoek-Sims A, Gendall P. A qualitative exploration of young adult smokers' responses to novel tobacco warnings. BMC Public Health 2013:13:609.

31. Durkin S, Biener L, Wakefield M. Effects of different types of antismoking ads on reducing disparities in smoking cessation among socioeconomic subgroups. Am J Public Health 2009;99:2217-23.

32. Lupton D. Discourse analysis: a new methodology for understanding the ideologies of health and illness. Aust J Public Health 1992;16:145-50.

33. Kelly M. The role of theory in qualitative health research. Fam Pract 2010;27:285-90.

34. Cheek J. At the margins? Discourse analysis and qualitative research. Qual Health Res 2004;14:1140-50.

35. Park ER, Chang Y, Quinn VP, et al. Perceived support to stay quit: what happens after delivery? Addict Behav 2009;34:1000-4. 